Volume 1 Number 2 (Fall/Winter 2015)

www.jheaonline.org

ISSN 2474-2309

doi:10.22461/jhea.4.7165

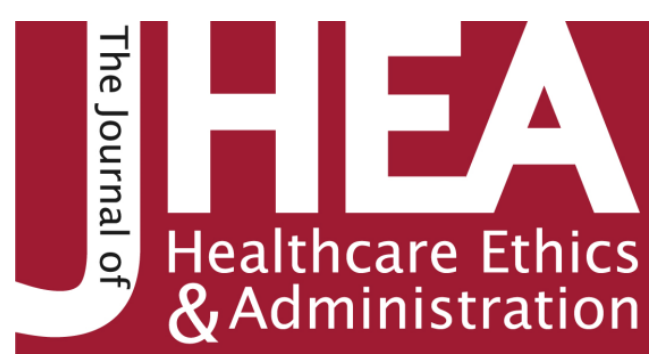

\title{
COMMENTARY \\ To Quarantine or Not to Quarantine: A Medical Perspective
}

This article appeared originally in The Internet Journal of Catholic Bioethics (Winter 2014).

KRYSTA CONTINO, M.D.

Gastroenterology Department, Cooper University Health Care, Camden, New Jersey, U.S.A.

*Address correspondence to: Gastroenterology Department, Cooper University Health Care, Camden, NJ 08103

Find this and more works at www.jheaonline.org

This work is brought to you for free and open access by the Institute of Clinical Bioethics (ICB) at Saint Joseph's University, Philadelphia, PA, U.S.A. It has been accepted for inclusion in The Journal of Healthcare Ethics \& Administration by editorial board and an authorized administrator of the JHEA. For more information, please contact admin@jheaonline.org 


\section{To Quarantine or Not to Quarantine: A Medical Perspective}

This article appeared originally in The Internet Journal of Catholic Bioethics (Winter 2014).

KRYSTA CONTINO, M.D.

Gastroenterology Department, Cooper University Health Care, Camden, New Jersey, U.S.A.

Keywords: tuberculosis, infectious disease, poverty.

Tuberculosis (TB) is an infection caused by mycobacterium tuberculosis, an acid-fast bacterium that is transmitted via aerosolized respiratory droplets. The organisms travel via infected droplets to the most distal portion of the respiratory tract, the alveoli, where they are consumed by macrophages. These cells are considered to be the "scavengers" of the immune system. Once the bacteria are engulfed, they are able to begin replicating inside of these cells. This results in either active pulmonary disease or disseminated infection following hematogenous spread of the organisms; however, TB can also become quiescent and reactivate later in life. ${ }^{1}$ According to the World Health Organization (WHO), approximately one third of the world's population is infected with latent TB. ${ }^{2}$

This infection is often said to be a disease of poverty as the majority of cases occur in the world's poorest countries, specifically in areas in which living quarters are close. ${ }^{3}$ This is evidenced by the fact that over $95 \%$ of deaths from TB occur in low- and middle-income countries. ${ }^{4}$ Some of the most severely affected regions of the world include southeast Asia and Sub-Saharan Africa. ${ }^{5}$ Tuberculosis is of particular public health interest as it is the second most common cause of death due to a single infection second only to HIV/AIDS. ${ }^{6}$

Patients with pulmonary tuberculosis undergo a two phase treatment plan. The two-month initiation phase is composed of daily administration of a four-drug regimen, which is comprised of isoniazid, ethambutol, rifampin and pyrazinamide. This comprehensive cocktail is necessary as there is always concern for isoniazid resistance. ${ }^{7}$ When two months of uninterrupted treatment have been successfully completed, the continuation phase is begun. Isoniazid and rifampin are continued for a minimum of 4 months but may be as long as 7 months. The time period of this second phase may be modified under certain circumstances, such as in the case of an immunocompromised individual, to ensure complete resolution of the active disease. ${ }^{8}$

Today, as with many other infectious agents, resistance of Mycoplasma tuberculosis to conventional therapy and standard antibiotics is becoming increasingly prominent. The WHO defines two subsets of TB as it relates to their

\footnotetext{
1 Thomas E. Andreoli, and Russell L. Cecil. "Infectious Diseases of the Lung." Andreoli and Carpenter's Cecil Essentials of Medicine. 8th ed. (Philadelphia, PA: Saunders/Elsevier, 2010), 256-57.

2 "Fact Sheet N¹04." Tuberculosis. World Health Organization, Feb. 2013, accessed Sept. 20, 2013, http://www.who.int/mediacentre/factsheets/fs104/en/.

${ }^{3}$ Nicki R. Colledge, Brian R. Walker, Stuart Ralston, and Stanley Davidson. "Infections of the Respiratory System." Davidson's Principles and Practice of Medicine. 21st ed. (Edinburgh: Churchill Livingstone/Elsevier, 2010), 688.

4 "Fact Sheet $\mathrm{N}^{\circ} 104 . "$

${ }^{5}$ Ibid.

6 Ibid.

${ }^{7}$ B. Eris-Gulbay, OU Gurkan, OA Yıldız, ZP Onen, FO Erkekol, A Bac-c-ıoglu, and T Acıcan, "Side Effects Due to Primary Antituberculosis Drugs During the Initial Phase of Therapy in 1149 Hospitalized Patients for Tuberculosis," Respiratory Medicine 100 (2006): 1834-1842

8 JL Johnson, DJ Hadad, R Dietze, EL Maciel, B Sewali, P Gitta, A Okwera, RD Mugerwa, MR Alcaneses, MI Quelapio, TE Tupasi, L Horter, SM Debanne, KD Eisenach, and WH Boom. "Shortening Treatment in Adults with Noncavitary Tuberculosis and 2-Month Culture Conversion," American Journal of Respiratory and Critical Care Medicine 180 no. 6 (2009): 558-63.
} 
susceptibility or lack thereof to the most effective anti-TB medications that exist. Multi-drug resistant TB (MDR-TB) is the title given to infection with organisms that are already resistant to or become resistant during treatment to isoniazid and rifampin, the first line drugs in the treatment of this disease. More concerning, however, is extensively drug resistant TB (XDR-TB). These strains have acquired mechanisms to prevent susceptibility to not only isoniazid and rifampin but also to fluoroquniolones and amikacin, kanamycin and capreomycin, the second-line injectable TB medications. If responsive to the drugs at all, the treatment course is usually 2 years in duration. ${ }^{9}$ This is concerning as XDR-TB has now been described in 84 countries with as many as $9 \%$ of all MRD-TB cases being extensively drug resistant. ${ }^{10}$ The alarming fact is that XDR-TB is associated with a higher probability of death and decreased treatment success when compared to MDRTB. 11

Reason for this resistance pattern is thought to be multifactorial: incorrect drug or dose choice, abbreviated treatment duration, poor-adherence to the regimen, or in many low income countries, lack of access to medication and supplies. ${ }^{12}$ A study recently performed in India, looked at the association between XDR-TB and various comorbidities. Researchers found that those with other medical maladies, such as diabetes, myasthenia gravis and thalassemias, had a higher tendency toward resistance. It was concluded that this was likely secondary to poor immune response leading to extended disease chronicity, and therefore, more of an opportunity for mutations to develop. Moreover, they looked at the socioeconomic status of those with XDR-TB and found that poor living conditions and poor nutrition as well as lack of access to health care put individuals at higher risk for developing resistance. Finally, they found that $94.4 \%$ of individuals with XDR-TB had previously been treated for TB, although the details of their treatment regimens could not be devised.13

One mechanism thought to decrease the likelihood of resistance is to identify and diagnose tuberculosis early and to continue treatment without interruption. In order to accomplish these goals, directly observed therapy [or DOT] was implemented. By assigning specific individuals to watch patients take their medications, the thought is that compliance with and completion of prescribed course of anti-TB drugs leads to a cure of their infection thereby not only preventing spread of the disease to others but also lessening the chance of drug resistance within the community. Despite the findings of a Cochrane review performed in 2007, which concluded that there was no significance in outcomes between DOT and self-administration of anti-TB drugs, DOT is frequently implemented in the treatment of high-risk patients. ${ }^{14}$

XDR-TB has been found not only in developing nations but also in the first world. An article published in Emerging Health Threats in 2012 flagged XDR-TB as one of the top 5 infections thought to present an overall threat to global public health with the reason being that in the setting of resistant strains, widespread transmission of the disease count be catastrophic. ${ }^{15}$ Whereas extremely resistant strains of Mycoplasma tuberculosis already exist, the concern has now arisen that completely resistant strains will present next. For this reason, it is imperative not only to preserve the efficacy of first and second-line TB treatments but to also investigate new TB drugs and encourage pharmaceutical companies to work toward development of such compounds. It has been more than 40 years since a new anti-TB drug was introduced into clinical practice. Currently, there are multiple novel drugs in the early stages of discovery of which one has now reached Phase II clinical investigation.

In the modern age of global travel, tuberculosis is no longer confined to strictly endemic areas; rather, it can present anywhere. For this reason, in those suspected of infection, it is imperative that the proper prevention techniques, such negative pressure isolation rooms when in the hospital and N95 masks be worn. Furthermore, it is imperative that those infected with this organism complete the full treatment course as increased prevalence of XDR-TB could clearly lead to a world-wide epidemic.

\section{REFERENCES}

\footnotetext{
9 "Multi-Drug Resistant Tuberculosis: 2013 Update," World Health Organization, Mar. 2013. Accessed Sept. 20, 2013, http://www.who.int/tb/challenges/mdr/MDR_TB_FactSheet.pdf.

10 "Executive Summary" [Tuberculosis] World Health Organization, 2012. Accessed Sept. 20, 2013, http://www.who.int/tb/publications/global_report/gtbr12_executivesummary.

${ }_{11}$ GB Migliori, R Loddenkemper, F Blasi, and MC Raviglione, "125 Years After Robert Koch's Discovery of the Tubercle Bacillus: the New XDR-TB Threat. Is "Science" Enough to Tackle the Epidemic?" European Respiratory Journal 29 no. 3 (2007): 423-27.

12 JA Singh, R Upshur, and N Padayatchi, "XDR-TB in South Africa: No Time for Denial or Complacency," PLoS Medicine 4 no. 1 (2007): 770-775.

${ }^{13}$ C. Porwal, A Kaushik, N Makkar, I Banavaliker, M Hanif, R Singla, A Bhatnagar, D Behera, I Pande, and U Singh, "Incidence and Risk Factors for Extensively Drug-Resistant Tuberculosis in Delhi Region," PLoS One 8 no. 2 (2013): e55299.

${ }_{14}$ J Volmink and P Garner, "Directly Observed Therapy for Treating Tuberculosis." Cochrane Database Systematic Review. 17 no. 4 (2007): CD003343.

${ }^{15}$ K. Christina, K. Ijaz, S. Dowell, C. Chow, R. Chitale, J. Bresee, E. Mintz, M. Pallansch, S. Wassilak, E. McCray, and R. Arthur, "What We Are Watching_Five Top Global Infectious Disease Threats, 2012: A Perspective from CDC's Global Disease Detection Operations Center," Emerging Health Threats Journal 3 no. 6 (2013): 20632.
} 
Andreoli, Thomas E., and Russell L. Cecil. "Infectious Diseases of the Lung." Andreoli and Carpenter's Cecil Essentials of Medicine. 8th ed. (Philadelphia, PA: Saunders/Elsevier, 2010)

Christina, K., K. Ijaz, S. Dowell, C. Chow, R. Chitale, J. Bresee, E. Mintz, M. Pallansch, S. Wassilak, E. McCray, and R. Arthur. "What We Are Watching-Five Top Global Infectious Disease Threats, 2012: A Perspective from CDC's Global Disease Detection Operations Center." Emerging Health Threats Journal 3 No. 6 (2013): 20632.

Colledge, Nicki R, Brian R. Walker, Stuart Ralston, and Stanley Davidson. "Infections of the Respiratory System." Davidson's Principles and Practice of Medicine. 21st ed. (Edinburgh: Churchill Livingstone/Elsevier, 2010).

Eris-Gulbay, B., OU Gurkan, OA Yıldız, ZP Onen, FO Erkekol, A Bac-c-ıglu, and T Acıcan. "Side Effects Due to Primary Antituberculosis Drugs During the Initial Phase of Therapy in 1149 Hospitalized Patients for Tuberculosis." Respiratory Medicine 100 (2006): 1834-1842

Johnson, JL, DJ Hadad, R Dietze, EL Maciel, B Sewali, P Gitta, A Okwera, RD Mugerwa, MR Alcaneses, MI Quelapio, TE Tupasi, L Horter, SM Debanne, KD Eisenach, and WH Boom. "Shortening Treatment in Adults with Noncavitary Tuberculosis and 2-Month Culture Conversion." American Journal of Respiratory and Critical Care Medicine 180 No. 6 (2009): 558-63.

Migliori, GB, R Loddenkemper, F Blasi, and MC Raviglione. "125 Years After Robert Koch's Discovery of the Tubercle Bacillus: the New XDR-TB Threat. Is "Science" Enough to Tackle the Epidemic?" European Respiratory Journal 29 No. 3 (2007): 423-27.

Porwal, C, A Kaushik, N Makkar, I Banavaliker, M Hanif, R Singla, A Bhatnagar, D Behera, I Pande, and U Singh. "Incidence and Risk Factors for Extensively Drug-Resistant Tuberculosis in Delhi Region." PLoS One 8 No. 2 (2013): e55299.

Singh, JA, R Upshur, and N Padayatchi. "XDR-TB in South Africa: No Time for Denial or Complacency." PLoS Medicine 4 No. 1 (2007): 770-775.

Volmink J, and P Garner, "Directly Observed Therapy for Treating Tuberculosis." Cochrane Database Systematic Review. 17 no. 4 (2007): CD003343.

World Health Organization. "Executive Summary" [Tuberculosis] 2012. Accessed Sept. 20, 2013, http://www.who.int/tb/publications/global_report/gtbr12_executivesummary.

World Health Organization. "Fact Sheet N¹04." [Tuberculosis]. Feb. 2013. Accessed Sept. 20, 2013, http://www.who.int/mediacentre/factsheets/fs104/en/.

World Health Organization. "Multi-Drug Resistant Tuberculosis: 2013 Update." Mar. 2013. Accessed Sept. 20, 2013, http://www.who.int/tb/challenges/mdr/MDR_TB_FactSheet.pdf. 